\title{
Suicide Ideation: Role of Psychological and Social factors among Indian Police Officers
}

\author{
Dr. Ritu Sekhri ${ }^{1}$
}

\section{ABSTRACT}

Suicide Ideation has been considered as an important antecedent of attempted suicide. It refers to the cognitive aspect of suicide, and may be considered an early detection of more serious suicidal behaviour. When people view their lives from negative perspective filled with emotional pain and distress, they inflate the consequences of their mistakes, start believing that they will continue to fail and should give up altogether. Police officers are almost under stress to meet the demands of the public and works under high stressful conditions as they have to keep the crime rate under control. They have no breaks, no vacations, no weekends and have to work in all weather conditions providing public with all comforts. The paper focuses on the psychological variables and demographic factors such as anxiety, depression, alcohol, age, gender, socioeconomic status, rank, years of service, years of current position, educational qualifications, marital status, presence of health-related problems that seems to play an important role in understanding the predictors of suicide ideation and suicide among Indian Police officers.

Keywords: Suicide Ideation, suicidal behaviour, psychosocial and demographic variables, Police suicide

Suicide has become one of the biggest social problems of our contemporary society affecting all our lives in one way or the other. It is a day-to-day experience and everyday news in our society. Moreover this still remains as a silent issue of discussion with less or no efforts being done to prevent or stop this act. The Oxford English Dictionary defines Suicide as an act of taking one's own life; one who dies by his own hands, self-murder. Suicide is the process of purposely ending one's own life. Emile Durkheim defines suicide as follows: “...the term suicide is applied to all cases of death resulting directly or indirectly from a positive or negative act of the victim himself, which he knows will produce this result.” The great nineteenth century French sociologist Emile Durkheim, in his book, Le Suicide (1897) illustrates the types of suicide. In this book he discusses four different kinds of suicide: Egoistic suicide, Altruistic suicide, Anomic suicide and Fatalistic suicide.

\footnotetext{
${ }^{1}$ Psychologist, Government Medical College \& Hospital, Sector-32, Chandigarh
} 
1. Egoistic Suicide: Egoistic Suicide is caused by lack of social integration of society in the religious sphere, domestic, and the political sphere. The more weakened the groups to which he belongs, the less he depends on them, the more he consequently depends only on himself and recognize no other rules of conduct that are founded on his private interests. The individual ego asserts itself to excess in the face of the social ego and at its expense; it may be called egoistic the type of suicide springing from excessive individualism (Durkheim, 1897).

2. Altruistic Suicide: Altruistic Suicide is characterized by a sense of being overwhelmed by a group's goals and beliefs. It occurs in societies with high integration, where individual needs are seen as less important than the society's needs as a whole. If excessive individuation leads to suicide, insufficient individuation has the same effects. When a man has become detached from society, he encounters less resistance to suicide in himself, and he does so likewise when social integration is too strong. Bartholin, in his book reports that Danish warriors considered it a disgrace to die in bed of old age or sickness, and killed themselves to escape this humiliation. The Goths likewise believed that those who die a natural death are destined to languish forever in caverns full of venomous creatures. So old men would throw themselves from the high pinnacle called 'The Rock of the Forefathers' and accordingly they assigned a delightful abode to those who commit.

3. Anomic suicide: This type of suicide is due to certain breakdown of social equilibrium, such as bankruptcy or after winning a lottery. In other words, anomic suicide takes place in a situation which has cropped up suddenly. It reflects an individual's moral confusion and lack of social direction, which is related to dramatic social and economic upheaval. It is the product of moral deregulation and a lack of definition of legitimate aspirations through a restraining social ethic, which could impose meaning and order on the individual conscience.

4. Fatalistic suicide: Fatalistic suicide is the opposite of anomic suicide. It happen when a person is excessively regulated, when their futures are pitilessly blocked and passions violently choked by oppressive discipline. It occurs in overly oppressive societies, causing people to prefer to die than to carry on living within their society. A good example would be that some people prefer to die than live in a prison with constant abuse and excessive regulation that prohibits them from pursuing their desires. This type of suicide is due to overregulation in society.

According to National Youth Mental health Foundation, 'suicidal ideation' refers to thoughts that life isn't worth living, ranging in intensity from fleeting thoughts through to concrete, well thought-out plans for killing oneself, or a complete preoccupation with self-destruction (www.headspace.org.au). Suicide ideation may be characterized as ranging from relatively mild, general thoughts and wishes that one were dead to serious ideation about specific plans and means of taking one's life. Schotte \& Clum (1982), as well as Bonner \& Rich (1987) found a relationship between the frequency of suicide ideation and the likelihood of attempts at suicide. 
Police suicide in India is a problem facing many law enforcement agencies. The problem is often ignored, misunderstood, misrepresented and under researched (Pienaar \& Rothmann, 2005). Suicide among members of the police has been described as an epidemic (Violanti, 1996). Studies report that police officers have higher suicide rates compared to the rates of the general population and those of other professions (Helmkamp, 1996). Suicidal behaviour may be categorized as consisting of suicide completion, suicide attempts, and suicidal ideation. It can be plotted on a continuum varying in severity from ideation to intent, attempt and completion (Reynolds, 1991b). Thus, suicidal behaviours occur in different forms that involve a degree of severity that can range from a person only wishing to be dead to actually killing him or herself (Schlebusch, 2005). The police force in India does not assume a positive image. Defined by a rigid bureaucratic cadre, the police personnel have to work not only to see that crime remains under control but also have to face 'systematic' interference from political masters and other influential sectors. On the personal count as well, the police personnel have perennial problems of basic working, living conditions and welfare facilities. Only two studies on suicide ideation of police members have been conducted in one of the nine provinces of South Africa (viz., the North West Province) (Rothmann \& Strijdom, 2002; Rothmann \& van Rensburg, 2002). These studies showed that $10.58 \%$ of the uniformed police members showed significant levels of suicide ideation. Hem, Berg \& Ekeberg (2001) recommended that suicide ideation be investigated in police populations. There can be different psychological predictors to study and predict the level of suicide ideation with an increase in those factors. Following psychological symptoms; stress, anxiety, low self-esteem, frustration, depression, family problems will be studied along with demographic variables that will help us in reviewing the suicidal behaviour and deaths among Indian Police Officers.

\section{FACTORS LEADING TO SUICIDE IDEATION AMONG POLICE OFFICERS}

O Psychological/Interpersonal

o Social/demographic

\section{Psychological/Interpersonal factors}

Stress is the psychological factor that is harmful to physical and psychological health and hazardous to quality life concept. Selye (1936) known as “The father of modern stress", brought to our attention, the concept of stress in a medical sense to indicate overloading of the human body.

Police officers play a very significant role for maintaining law and order in the society despite all the shortcomings and limitations in the Police Department especially with regard to the infrastructure facilities, manpower and periodic training. Police Officers are supposed to implement all the criminal laws for which they work round the clock and/or without any leave/break, which cause tremendous mental pressure and physical exertion on them. As a result a few of them may have violent outbursts. Campbell (1970) discussed the conflicting roles and demands involved in the order maintenance, community service and crime fighting 
responsibilities as an important source of frustration in police. The amount of social prestige and esteem the police in India enjoy does not require any elaboration. The subordinate ranks are so low paid that corruption has become an accepted thing. The fact that a police officer is supposed to be all the twenty four hours on duty should be duly reflected in the pay scales. They do not enjoy even the fundamental rights that other public servants enjoy. They had to do night duty not less than fifteen days a month and need to be compensated for night duty, working overtime and occupational hazards (Xavier \& Prabhakar, 2013). Further, there are conflicting job demands, responsibilities of subordinates, time pressure and deadlines, physical strain of work environment, long hours and having to cope with changes at work and expenses (monetary and career) of making mistakes. It is seen that since subordinates are incapable of performing their tasks properly, the senior officers tend to take on their responsibilities also. Increased accountability of any act within their area of jurisdiction, political interference, fear of explanation of any indiscipline or irresponsibility on the part of subordinates, lack of communication and cooperation from other departments result in unresolved frustrations and personal conflicts which further lead to stress and anxiety among officers at higher levels (Xavier \& Prabhakar, 2013).

Violanti (1995) stated that when officers lose the ability to cope in normal ways, they may turn to an ultimate solution to relieve the pressure of stress. Hopelessness is the most motivating contributor to the suicidal mind set. One feels that he or she does not have control over one's own behaviour, feelings, or circumstances. It is not rapid. It grows slowly, unabated, until it becomes an undefeatable mind set (Stewart, 1988).

Depression has been speculated to be a critical occurrence in the police population. A study conducted by the New York Police Department concluded that the suicide rates among New York police Department officers (at about 29 per 100000 annually) were considerably higher than among the general United States population (11.7 per 100000 in 1992). Ivanoff (2002) and other experts believe that police suicides are under reported, often classified as accidents in part to spare an officer's family from embarrassment, a study on suicide amongst the police concluded that the statistical average of police suicides is much higher than that of the general population, within that average lies a notable increase experienced among older officers and those officers facing suspension. It is seen that in Indian police force, police men in higher ranks have increased work load and areas of jurisdiction.

\section{Social/ demographic factors}

Available studies of suicide ideation suggest a variety of demographic factors that can be responsible for suicidal behaviours and deaths among police officers. Sorenson and Rutter (1991) found that unmarried and younger individuals (compared with married and older individuals) showed higher levels of suicide ideation. Higher levels of suicide ideation have been shown for those who are depressed, dissatisfied, pessimistic, and who experience a sense of hopelessness (Breslau, 1992; Kandel, Raveis \& Davies, 1991; Sorenson \& Rutter, 1991; Kinkel et al., 1988; Smith \& Crawford, 1986) and frequent pains, such as stomach pain, headaches and 
migraines (Ingersoll, Grizzle, $\quad$ Beiter \& Orr, 1993; Breslau, 1992;). Individuals who abuse alcohol or drugs also show higher levels of suicide ideation (Sorenson \& Rutter, 1991; Slap, Vorters, Chaudhuri \& Centor, 1989; Smith \& Crawford, 1986; Topol \& Reznikoff, 1982). Several other studies reported that respondents who scored high on suicide ideation were more likely to have poor health (De Man \& Leduc, 1995; Lewinsohn, Rohde \& Seeley, 1994; Kandel et al., 1991). Janik and Kravitz (1994) found that marital problems and job suspension were important contributing factors to police officers' decisions to attempt suicide. Supportive families can buffer and diminish the occupational stresses that police officers experience (Graf, 1986). Constables and Sergeants are the rank structure that works at the grassroots level (Minnaar \& Mistry, 2006) and are often burdened with the operational level of policing, where they are exposed to scenes of violence and crime (Pienaar et al., 2007). They are the ones who are most likely to interact with suspects and members of the public on a daily basis. However, they are also likely to be involved in shooting incidents and common assaults (Minnaar \& Mistry, 2006). Police officers with lower ranks and poor qualifications are especially likely to be confined to an impoverished environment and lack alternative employment and advancement opportunities (Pienaar \& Rothmann, 2003). International research results indicate that older police officers have been in law enforcement longer, achieved higher rank and were also more likely to be assigned to sections where they perform fewer patrol duties (Patterson, 2001).

Swanepoel \& Pienaar's (2004) results indicated that gender is predictive of current suicide ideation, while Pienaar \& Rothmann's (2005), national study contends that males (compared to females) showed higher than expected frequencies of high suicide ideation. "Within civilized societies women are defined, accepted and recognized only to the extent to which their existence and behaviour is consistent with their naturally determined sexual and biological function. Thus, women become convinced of the natural necessity of their position." (Petrović, 2007). Such social attitudes resulted in the struggle (which continues today) of women against prejudice, conservative thinking and patriarchal stereotypes, obstacles to women's integration into certain professions, especially the police*

Historically, in 1900 Canada recruited the first women into the police service, to work on supervision tasks in detention institutions and in the prevention of juvenile crime. Their tasks were to "care for social order and peace, or the care of morals, abandoned children, female youth and prostitutes" (Janković, 1926). Reports indicate that women police officers, compared to their male colleagues, are more exposed to sexual harassment and violent and threatening situations at work, as well as to domestic violence (Brown \& Heidenshohn, 2000). These adverse situations can heighten the risk of suicide attempts. Buchanan et al. (2001) have identified gender differences in terms of what newly recruited policewomen and policemen experience during their first year at work. Of the ten most traumatic experiences during that year, men experience a

\footnotetext{
* Note, in this respect, that it was only during the second half of the 19th century that the doors of universities and faculties became open to women for education, and that it was only in the 20th century that it became possible for women to undertake social-political engagement. And as a response to the economic freedom gained through work and income outside the family, there resulted discrimination and segregation (women were paid less than men for the same job).
} 
greater proportion of physical attacks, while women experience various forms of sexual harassment. Pancheri et al. (2002) confirmed that women in the traffic police experience the highest degree of anxiety, depression and aggression.

Marital status affects the life of a police officer to great extent. When he arrives at work his role changes and his job demands to leave all the personal issues of his life and serve the nation. This alone can be very stressful at times especially when the personal life is very complex and demands equal attention. Sharing personal problems with co-workers also can change the attitude of all those working in the same workplace and can be misused by others. And one can consider the end of the life as one and the only solution to come out of the problematic situation. Unmarried police officers can also feel the pressure at the workplace as less family pressure can be expected on them. And this can at times worsen the situation by creating more of frustration and a need of a family or a life- partner with whom they can think of sharing their problems and can make them lonely. They may report higher levels of stress while performing tasks in isolation.

\section{MEASURES TO CONTROL THE RATE OF SUICIDE AMONG POLICE OFFICERS}

The long working hours, poor working conditions, VIP protection duty, festivals and lack of structural reforms can increase the stress level. Long term stress causes depression suicide. Therefore, regular screening for mental health problems during a physical check up can be provided for police personnel. The department can provide counseling to all the officers by recruiting special counselors with training in how to deal with stress and frustration. Workshops, talks, yoga and some meditational classes can be taken up with them to help them control their anger and channelize their destructive energy in a healthy way. Talking therapy where officers feel free to talk about their likes and dislikes, can express their inner thoughts in front of a counselor can be arranged. And at the same time it is the prime duty of a counselor to tackle such issues sensitively and avoiding disclosure to any other senior authority until it is for the sake of former's health. Few role play games can also be involved.

\section{CRITICAL ANALYSIS}

The job of a police officer demands lot of responsibility. He is expected to be loyal, dutiful, and polite. But at the same time we common people should also give them respect, appreciation, motivation for their effortful work. The nature of their job leaves them with so much of depression, frustration and stress and that the Police department must have stress managers, counselors, or psychologists which can help them in the state of their crisis.

"Three cheers to Indian Police Officers". 


\section{REFERENCES}

Bonner, R. L., \& Rich, A. R. (1987). Toward a predictive model of

suicide ideation and behavior: Some preliminary data in college students. Suicide and Life-Threatening Behavior, $\quad 17,50-63$.

Breslau, N. (1992). Migraine, suicide ideation, and suicide attempts. Neurology, 42, 392-395.

Brown, J., \& F. Heidenshohn. Gender and Policing: Comparative Perspectives. Basingstoke: MacMillan, 2000.

Buchanan, G., Stephens, C., \& Long, N. (2001). ”Traumatic events of new recruits and serving police.“ Australian Journal of Disaster and Trauma Studies, 5, 96-107.

Campell, J.S. (1970): Law and Order Reconsidered: Report of Task Force on law Enforcement to the National Commission on the Causes and Prevention of Violence, New York: Banton Book.

Clarke-Stewart, A. (1988). Lifelong Human Development, New York: John Wiley \& Sons, 430-432

de Man, A. F., \& Leduc, C. P. (1995). Suicide ideation in high school students: Depression and other correlates. Journal of Clinical Psychology, 51, 173-181.

Durkheim, E. (1897). Le suicide. Alcan. Paris.

Graf, F. A. (1986). The relationship between social support and occupational stress among police officers. Journal of Police $\quad$ Science and Administration, 14, 178-186.

Helmkamp, J.C. (1996). Occupation and suicide among males in the US Armed Forces. Suicide and Life- Threatening Behavior, 24, 267-274.

Hem, E., Berg, A. M., \& Ekeberg, Q. (2001) Suicide in police: A critical review. Suicide and Life-Threatening Behavior, 31, 224-233.

Ingersoll, G. M., Grizzle, K., Beiter, M., \& Orr, D. P. (1993). ～Frequent somatic complaints and psychosocial risk in adolescents. Journal of Early Adolescence, 13, 67-78.

Ivanoff, (2002). Police Suicide Study Recommends Additional Training Counseling, Columbia University record, 20, 2, Online Internet file://A:/record /2002.14html

Janik, J., \& Kravitz, H. M. (1994). Linking work and domestic problems with police suicide. Suicide and Life-Threatening Behavior, 24, 267-274.

Janković, Z. (1926). Women in police. Police br, 11, 296-299.

Kandel, D. B., Raveis, V. H. and Davies, M. (1991). Suicide $\quad$ ideation in adolescence: depression, substance use, and other risk factors. Journal of Youth and Adolescence, 20, 289-308.

Kinkel, R. J., Bailey, C. W., \& Josef, N. C. (1988). Suicide ideation in normal adolescents. University of Michigan, Flint.

Lewinsohn, P. M., Rohde, P., \& Seeley, J. R. (1994). Psychosocial risk factors for future adolescent suicide attempts. Journal of Consulting and Clinical Psychology, 62, 297305.

Minnaar, A., \& Mistry, D. (2006). Dealing with the use of force and stress related violence by members of the police: Some observations from selected case studies in Gauteng. Acta Criminologica, 19, 29-63. 
Pancheri, P., Martini, A., Tarsitani, L., Rosati, M., Biondi, M., \& Tomei, $\quad$ F. $\quad$ (2002). Assessment of subjective stress in the municipal police force in the city of Rome. Stress and Health. Journal of the International Society for the Investigation of Stress, 18, 127-32.

Patterson, G. T. (2001). The relationship between demographic variables and exposure to traumatic incidents among police officers. The Australasian Journal of Disaster and Trauma Studies, 2.

Petrović, D. (2007). Women in police throughout history. Security MUP Republike Srbije, 330341.

Pienaar, J., \& Rothmann, S. (2003). Suicide Ideation, Stress and Coping in the South African Service. Paper presented at the 11th European Congress of work and Organisational Psychology, Lisbon, Portugal.

Pienaar, J., \& Rothmann, S. (2005). Suicide Ideation in the South African Police Service. South African Journal of Psychology, 35, 58-72.

Pienaar, J., Rothmann, S., \& van de Vijer, F. J. (2007). Occupational Stress, Personality Traits, Coping, Strategies and Suicide Ideation in the South African Police Service. Criminal Justice and Behavior, 34, 246-258.

Reynolds, W. M. (1991b). Psychological characteristics of the Adult Suicide Ideation Questionnaire with college students. Journal of Personality Assessment, 56, 289-307.

Rothmann, S., \& Strijdom.G. (2002). Suicide Ideation in the South African Police Services in the North West Province. South $\quad$ African Journal of Industrial Psychology, 28, 44-48.

Rothmann, S., \& Van Rensburg, P. (2002). Psychological Strengths, Coping and Suicide Ideation in the South African Police Service in the North West Province. South African Journal of Industrial Psychology,28, 39-49.

Schotte, D. E., \& Clum, G.A. (1982). Suicide Ideation in a college population: A test of a model. Journal of Consulting and Clinical Psychology, 50, 690-696.

Schlebusch, L. (2005). Suicidal Behaviour in South Africa. Pietermaritzburg: University of KwaZulu Natal Press.

Selye, H. (1936). A syndrome produced by diverse nocuous $\quad$ agents, Nature, 138, 32.

Slap, G. B., Vorters, D. F., Chaudhuri, S., \& Centor, R. M. (1989). Risk factors for attempted suicide during adolescence. Pediatrics, 84, 762-772.

Smith, K., \& Crawford, S. (1986). Suicidal behavior among 'normal' high school students. Suicide and Life- Threatening Behavior, 16, 313-325.

Sorenson, S. B., \& Rutter, C. M. (1991). Transgenerational patterns of suicide attempt. Journal of Consulting and Clinical Psychology, 59, 861-866.

Swanepoel, C., \& Pienaar, J. (2004). Coping, Stress and Suicide Ideation in the South African Police Service in Gauteng Province. Acta Criminologica,17, 17-33.

Topol, P., \& Reznikoff, M. (1982). Perceived peer and family relationships, hopelessness and locus of control as factors in adolescent suicide attempts. Suicide and LifeThreatening Behavior, 12, 141-150.

Violanti, J. M. (1996). Police Suicide: Epidemic in blue. Springfield, IL: C. C. Thomas. 
Violanti, J. (1995). "The Mystery Within, Understanding Police Suicide" FBI Law Enforcement Bulletin, 19-23.

Xavier, P., \& Prabhakar, K. (2013). Stress among Indian Police and Conceptual Issues. International Monthly Refereed Journal of Research In Management \& Technology, Vol.2, 60-66. 